\title{
TERRITÓRIOS, PAISAGENS E REPRESENTAÇÕES: um diálogo em construção
}

\author{
territories, landscapes and representations \\ Maria Geralda de Almeida* \\ Maria Augusta Mundim Vargas** \\ Geisa Flores Mendes***
}

\section{Resumo}

As concepções de território e de paisagens para os geógrafos da abordagem cultural são de um ponto de vista no qual se deve permear mais humanidade ao "ler" o espaço, isto é, considerar como os homens criam os territórios e paisagens, como atribuem um significado e lhes dão sentido. Para esses geógrafos, é apreender que no espaço a materialidade tangível está banhada de elementos imateriais e intangíveis. Neste artigo, procurou-se refletir sobre essa dimensão humana, pela abordagem da geografia cultural com o enfoque nos territórios culturais, nas paisagens culturais e na cartografia.

Palavras-Chave: Territórios culturais, paisagens culturais, cartografia cultural, Geografia.

\section{Abstract}

The concepts of territory and landscape, for the geographers of the cultural approach, are a point of view in which humanity must permeate more to "read" the space that is, consider how men create territories and landscapes as an attribute meaning and give them a direction. For those geographers, is to apprehend that in the space, a tangible materiality is bathed of immaterial and intangible elements. In this article we tried to reflect of this human dimension, from the perspective of cultural geography with a focus on cultura territories, cultural landscapes and cartography.

Key words: Cultural territories, cultural landscapes, cultural cartography, Geography.

\section{Resumen}

Las conceptiones de territorio y paisajes, para los geógrafos de la abordagen cultural, son de un punto de vista en que la humanidad debe impregnar a "leer" el espacio, es decir, considerar cómo los hombres crean los territorios y paisajes de cómo atribuen un significado y darles un sentido. Para los geógrafos, es comprender que en el espacio la materialidad tangible está bañada de elementos imateriales e intangibles. En este artículo tratamos de reflexionar sobre esa dimensión humana, por la abordagen de la geografia cultural con el enfoque en los territorios culturales, en las paisajes culturales y en la cartografía.

Palabras clave: Territorios culturales, paisajes culturales, cartografía culturales, Geografia.

(*) Bolsista Produtividade - CNPQ, Prof ${ }^{a}$. Dr ${ }^{\mathrm{a}}$. do Programas de Pós-Graduação em Geografia da Universidades Federais de Goiás e de Sergipe - Caixa Postal 131, CEP. 74.001 970, Goiânia (GO) Brasil ,Tel: (+55 62) 35211170 ramal 228 - mgdealmeida@ gmail.com

(**) Programa de Pós-Graduação em Geografia da Universidade Federal de Sergipe - Av. Marechal Rondon s/n, NESA Rosa Elze, CEP: 49100-000 - Sao Cristovao (SE) - Brasil, Tel: (+55 79) 21056782 - amundim@infonet.com.br

(***) Prof ${ }^{\text {a }}$. Dr ${ }^{\mathrm{a}}$. da Universidade Estadual do Sudoeste da Bahia - Estrada do Bem Querer, Km 04, CEP: 45.000-000 - Vitoria da Conquista (BA) - Brasil, Tel: (+55 77) 34248600 geisauesb@yahoo.com.br 


\section{INTRODUÇÃO}

Das margens cheias de arbustos onde inúmeros homens pescavam com seus caniços, e do delta sonolento que se espreguiçava pela terra avermelhada adentro, o rio sinuoso com sua corrente murmurante enrolavase como uma serpente ao redor de Algiers, com um som indistinto. Entorpecida, peninsular Algiers, com todos os seus mutirões e cânticos de trabalho dando a impressão que seria algum dia levada pelas águas. O sol declinava, besouros esvoaçavam, as águas assustadoras gemiam. (KEROUAC, 2006).

O espaço geográfico, para certos geógrafos, é concebido como um espaço existencial e nele os territórios e lugares são entendidos como porções imbuídas de significados, de emoções e de sentimentos. Tal concepção remonta umas três décadas, quando aflorou uma perspectiva inovadora na geografia, que propõe ao geógrafo uma maior e melhor apreensão das relações que os homens mantêm com seu entorno, de como eles criam lugares, de como atribuem um significado ao espaço e dão um sentido de lugar a ele. Entre esses autores citam-se Tuan (1983), Claval (2001, 2004, 2008), Andreotti (2008) e Cosgrove (1998). A materialidade tangível do espaço está banhada de elementos imateriais e intangíveis que se revelam nas paixões, nos conflitos, nos risos, nas dores, nos encantamentos, nas cores, nas sonoridades e nos odores, tal como faz Keroauc na epígrafe destacada no início deste artigo, ao apresentar o sentido de lugar na descrição da cidade de Algiers, no vale do rio Mississipi.

Essa perspectiva inovadora implica em uma outra forma de interpretar e de fazer a geografia. É a que propõe Cosgrove (1998), quando trata a geografia como uma humanidade e como uma ciência social. Esse é um desafio para os geógrafos que querem trilhar outras abordagens teóricas e metodológicas na ciência geográfica, estabelecendo uma conciliação entre ciência e arte, razão e sentimento. Nas considerações desse artigo, produzido a três mãos, procura-se refletir essa dimensão humana, tomando a geografia cultural como viés. O enfoque recai nos territórios e paisagens culturais e na cartografia com a pretensão de, modestamente, alimentar a manutenção do interesse pelo tema. Nesse sentido, as partes se entrelaçam como dimensão uma das outras e, propositadamente, não apresentamos um desfecho nas considerações finais.

\section{TERRITÓRIOS CULTURAIS: tessituras de um discurso em construção}

As expressões Territórios Culturais ou Territórios de Identidade têm circulado intensamente no âmbito de diferentes áreas do conhecimento. Parece mesmo que a temática está na "crista da onda". Tais conceitos, além de presentes na esfera acadêmica, têm sido contemporaneamente utilizados em instâncias governamentais ao se estabelecer políticas públicas por meio da definição e da delimitação de Territórios Culturais ou Territórios de Identidade.

As discussões que associam território, cultura e identidade demonstram que enfoques culturais, seja no âmbito da Geografia ou de outras áreas do conhecimento, têm assumido uma posição privilegiada e desafiadora. Embora intervenções contemporâneas, pautadas nos territórios culturais ou territórios de identidade, muitas vezes, sejam encaminhadas de forma enviesada e desprovida de um real entendimento do que seja a cultura, a identidade e as representações, é inegável que tal processo instiga um "olhar" mais apurado sobre as articulações que se processam entre território, cultura e identidade.

Geógrafos, com perspectivas de análises diversas, a exemplo de Claval (2004), Cosgrove (1998), Del Río (1998) dentre outros já explicitaram que enraizamentos culturais estão impregnados de "signos" e referentes geográficos. Nesse aspecto, demarca-se aqui a adoção do conceito de território para Haesbaert (2004, p. 42), para quem a acepção dessa categoria deve envolver “[...] ao mesmo tempo, a dimensão espacial material das relações sociais e o conjunto de representações sobre o espaço ou o 'imaginário geográfico' que não apenas move como integra ou é parte indissociável destas relações.” Esse imaginário geográfico ou imaginário territorial para Moraes (2005, 
p. 59) "[...] articula uma dialética entre a construção material e a construção simbólica do espaço, que unifica num mesmo movimento processos econômicos, políticos e culturais".

A compreensão explicitada pelos autores mencionados, além de destacar a importância das dimensões mais objetivas, permite também realçar, na análise dos territórios, os aspectos voltados para os elementos subjetivos e simbólicos. Almeida (2003, p. 108) enfatiza tal acepção ao afirmar que território "[...] é também objeto de operações simbólicas e é nele que os atores projetam suas concepções de mundo".

Na apreciação da dimensão cultural do sertão sergipano, por exemplo, Almeida e Vargas (1998, p. 472) ressaltam que "as expressões culturais materializam-se no espaço" e demonstram que a dimensão cultural "[...] talha os indivíduos, define os meios de se relacionarem, de organizarem o espaço e de se organizarem nele.” (ALMEIDA; VARGAS, 1998, p. 470).

Diante de tais considerações, as autoras apresentam aspectos que evidenciam a relação entre território e cotidiano, dimensão territorial e dimensão cultural, ao mesmo tempo em que os discutem. A compreensão dessas relações permite afirmar que a apreensão dos vínculos entre território e cultura é de extrema importância para o olhar geográfico.

É assim que a busca da superação da dicotomia material/ideal na discussão da categoria território tem sido empreendida por alguns geógrafos. Conforme destaca Saquet (2007), durante a década de 1980 e, sobretudo, a partir dos anos 1990, as abordagens sobre território sofreram alterações significativas, pautadas especialmente no reconhecimento e na explicação de aspectos simbólico-culturais vinculados às bases territoriais.

Sobre tal questão, Haesbaert (2004, p. 42) esclarece: “[...] para muitos, pode parecer um contra-senso falar em 'concepção idealista de território', tamanha a carga de materialidade que parece estar 'naturalmente' incorporada ao termo". Não se trata, contudo, de discutir a primazia de uma ou de outra dimensão na análise do território, mas considerá-lo em sua totalidade, o que certamente suscita o reconhecimento e a importância de levar em conta tanto as dinâmicas materiais quanto as imateriais. Endossa-se, nesses aspectos, a postura desse autor (2004, p. 79), quando pondera que “[...] o território pode ser concebido a partir da imbricação de múltiplas relações de poder, do poder mais material das relações econômico-políticas ao poder mais simbólico das relações de ordem mais estritamente cultural”. Del Río (1998), com um entendimento semelhante, enfatiza:

Y es que en ocasiones tendemos a relegar a un segundo plano los lazos afectivos, emocionales... ante la dificultad de ser traducidos a una lógica racionalista. Pero razón e irracionalidad son inherentes al ser humano, y también forman parte de su actuación e identificación, en y como grupo en un espacio y tiempo concretos. Espacios y tiempos configurados en buena medida desde la interacción diaria de los individuos que conviven cotidianamente, pero que sin embargo se estructuran en marcos territoriales delimitados en gran parte desde la lógica del poder político-institucional, que organiza el espacio en estructuras más amplias (DEL RIO, 1998, p. 136).

Mais uma vez, concordando com o autor, ressalta-se a necessidade de considerar a intensa relação entre os elementos materiais e imateriais que compõem o processo de produção socioespacial. Reconhecendo a riqueza que o entrecruzamento de proposições teóricas possibilita, Almeida (2005, p. 108) afirma:

Como organização do espaço, pode-se dizer que o território responde em sua primeira instância, a necessidades econômicas, sociais e políticas de cada sociedade e, por isso, sua produção está sustentada pelas relações sociais que o atravessam. Sua função, porém, não se reduz a essa dimensão instrumental; ele é também objeto de operações simbólicas e é nele que os atores projetam suas concepções de mundo.

Levando em conta tais aspectos, território desdobra-se em territorialidade, conceito que tem sido utilizado para enfatizar as questões de ordem simbólica e cultural e o sentimento de pertencimento que Almeida (2005, p. 109) destaca como “[...] resultado de uma apropriação simbólico-expressiva 
do espaço, sendo portador de significados e relações simbólicas”. Diante de tal constatação, é inevitável concluir que a identidade cultural também dá sentido e significado ao território. Enfim, a intensa articulação entre todas as dimensões é que vai possibilitar uma compreensão da totalidade dos fenômenos que se manifestam no território.

Compreende-se ainda que as denominações dos territórios e o seu mapeamento atuam como um porto seguro para a memória. De acordo com Claval (2001, p. 202), a toponímia é um dos traços mais acentuados da herança cultural: “[...] é, frequentemente, marcada por um grande conservadorismo: guardam-se através da história os nomes antigos". Alterar a denominação de um território, de um lugar, implica, muitas vezes, demover a história ali vivida. Retirar uma dada denominação do mapa ou não reconhecer a sua configuração corresponderia a apagá-la da memória.

Del Río (1998, p. 135) desenvolve uma reflexão semelhante e apresenta o seu ponto de vista acerca da categoria território, argumentando, enfaticamente, que

[...] el territorio se construye a partir de unos intereses concretos, más o menos racionalizados, pero también a través de una lógica relacionada con otros aspectos que en ocasiones son relegados a un segundo nivel, pero que tienen una importancia fundamental: los aspectos emocionales, los afectivos, e incluso si se quiere los aspectos "irracionales". La vinculación persona-grupo-territorio a través de los procesos de identificación es una buena muestra de ello.

O entendimento dos autores apontados corrobora a necessidade de se conceber o território também pelo viés de sua dimensão cultural, entretanto, alguns equívocos têm permeado as análises desenvolvidas e amplamente divulgadas especialmente nos programas governamentais. Muitas vezes, o que tem prevalecido é que se tem utilizado os mesmos critérios clássicos para o desenho e a cartografia dos territórios culturais. Como pensar cultura e identidade considerando apenas o fixo, o pronto, o acabado se a própria identidade está em constante processo de fazer-se, se está sempre em curso?

É nesse contínuo movimento de fazer-se que os territórios, as paisagens, os lugares e as suas representações são constantemente rasurados, reinterpretados e reescritos. Tal movimento é fundamental e inerente à própria dinâmica socioespacial, uma vez que o espaço como conceito e especificidade da geografia "[...] é a um só tempo produto e processo histórico, um mosaico de relações, formas, funções e sentidos" (SERPA, 2006, p. 11). Assim, torna-se necessário, sobretudo, “[...] pensar o espaço como algo dinâmico e mutável, reflexo e condição da/para a ação dos seres humanos, como espaço vivido e, por isso mesmo, 'representável', algo passível de 'apropriação"” (SERPA, 2006, p. 15).

Daí, na análise de territórios culturais, vale pensar no questionamento: “[...] de um espaço assim, movente e infinito que se afunila para dentro da gente, como compor um mapa?" (MELO, 2006, p, 117). Esse questionamento suscita, imediatamente, a necessidade de se pensar no conceito de identidade.

Como assegura Hall (1999), o conceito de identidade é demasiadamente complexo e multifacetado, sendo, portanto, impossível pensá-lo no âmbito de afirmações conclusivas. A variedade de abordagens e de concepções que permeiam tal conceito evidencia a sua emergência e a sua importância também nas análises geográficas, além de apontar para a riqueza de temáticas que podem ser perpassadas por tal discussão.

Interessa, especificamente, na análise aqui realizada, o entendimento de que "[...] a identidade social é também territorial quando o referente simbólico central para a construção desta identidade parte do ou traspassa o território", feita por Haesbaert (1999, p. 179). Tal acepção gera uma espécie de pertencimento a um determinado recorte territorial.

De antemão, demarca-se que a abordagem da identidade associada ao território deve aqui ser entendida por meio do pressuposto apontado por García Canclini (2006, p. 117), ao enfatizar que esta não é uma essência intemporal que se manifesta, antes é “[...] uma construção imaginária que 
se narra". Tal assertiva coincide, ainda, entre outros autores, com a interpretação de Clifford (1995), o qual enfatiza que a identidade é conjuntural e não essencial.

Os argumentos desenvolvidos especialmente por García Canclini (2006, p.145) estabelecem a compreensão de que a identidade, associada ao território, é instituída pelo conjunto das "vias de comunicação". Assim, a identidade, de fato, é uma construção, mas “[...] o relato artístico, folclórico e comunicacional que a constitui se realiza e se transforma em relação a condições sócio-históricas não redutíveis à encenação" (GARCÍA CANCLINI, 2006, p. 138). É delineada, simultaneamente, por materialidades e imaterialidades, aspectos objetivos e subjetivos, permanências e rupturas.

Como pensar, então, em territórios culturais considerando uma identidade coesa com o território se os próprios sentidos a ele atribuídos são diversos, múltiplos? Tal aspecto foi analisado e demonstrado por Mendes (2009) em estudo acerca da multiplicidade de sentidos atribuídos a sertão. Isso posto, torna-se necessário reafirmar, em concordância com Massey (2008, p. 111), que os territórios "[...] em vez de serem localizações de coerência, tornam-se os focos do encontro e do não encontro, do previamente não relacionado e, assim, essenciais para a geração do novo". O espacial, ao ser permeado por distintas temporalidades, gera, ininterruptamente, novas configurações, que, certamente, desencadeiam persistências e/ou reconfigurações identitárias. A discussão da identidade remete, portanto, inevitavelmente, à compreensão da alteridade e às relações de pertencimento e não pertencimento que se atrelam ao território.

Ponderando aspectos do momento atual em que "[...] espaço e tempo se cruzam para produzir figuras complexas de diferença e identidade, passado e presente, interior e exterior, inclusão e exclusão", Bhabha (1998, p. 19) demonstra que o movimento é que vai dar a característica principal à análise, neste caso, dos territórios. Assim, a utilização de termos, como passagem intersticial, hibridismo, entrelugares, evidencia a percepção não estática e monolítica do espaço e da cultura. A abordagem que envolve território, cultura e identidade deve ser, portanto, calcada essencialmente no dinamismo e no movimento.

No que concerne aos Territórios de Identidade, a intenção é a de apresentar um projeto e uma cartografia que valorizem mais os aspectos ditos identitários e culturais do que os critérios técnicos, econômicos e naturais. Mesmo em se tratando de uma proposta considerada mais cultural, o mapeamento dos Territórios de Identidade não reflete um processo de identificação real, uma vez que este está sempre em curso.

Tais constatações afinam-se com a advertência apresentada por Almeida (2008, p. 61) quanto ao risco de se fazer leituras e discursos sobre determinados territórios considerando-os como uma sociedade, uma paisagem e um território único.

As representações assim constituídas, que classificam os espaços, que atribuem valores aos territórios e que conformam imagens dos lugares, não podem ser consideradas neutras nem puramente objetivas. Implicam, também, atribuições de sentidos em consonância com relações sociais de poder. Traduzir um território em discursos e representações requer um fenômeno de percepção que é marcado também por um complexo conjunto de "lógicas sociais" (PESAVENTO, 1995, p. 287).

As abordagens destacadas legitimam a necessidade sublinhada por Penna de "[...] se abandonar qualquer enfoque da identidade que a conceba necessariamente como monolítica, única ou estável, ou ainda como dotada de existência própria" (PENNA, 1992, p. 56). Partindo dessa compreensão, é inevitável a conclusão de que muitos laços de identidade se manifestam na convivência com o lugar, com o território. Os significados desses laços, porém, não são marcados pela unicidade, mas sim pela multiplicidade de sentidos.

\section{VISITANDO AS PAISAGENS CULTURAIS}

Entre as categorias caras à Geografia encontra-se também a paisagem. Os geógrafos interessados nessa categoria desenvolveram uma "maneira de ver", uma forma de organizar e compor o mundo externo em uma "cena", com seus elementos materiais e imateriais. Cosgrove (1998), que 
teve um entendimento luminoso sobre a paisagem, dizia ser esta uma nova maneira de ver o mundo, como uma criação racionalmente ordenada, cuja estrutura e mecanismos são acessíveis à mente humana. Entender e interpretar a paisagem implica, pois, em uma visão de mundo de quem o faz. Paisagem, na concepção da geografia cultural, diz respeito à nossa posição na natureza, de que sua elaboração se dá pela percepção e pela razão humana e que ela sempre esteve ligada com a cultura.

Os geógrafos que lidam com essa abordagem são sensíveis à dimensão cultural das paisagens. Nas palavras de Claval (2004, p. 40),

[...] observam os marcos e sinais visíveis sobre o terreno: as igrejas nas pequenas cidades, as cruzes ao longo dos caminhos, os minaretes, os cemitérios de geometrias indecisas [...]. É viajando, familiarizandose com as paisagens diferentes que os geógrafos se tornam sensíveis a esses marcos, cuja presença repetida é sinal de pertencimento, de reconhecimento, de confirmação de identidades.

Tais marcos foram levados em conta pela Organização das Nações Unidas para Eduação, Ciência e Cultura (UNESCO), ao elaborar sua Convenção de Patrimônio Mundial. De acordo com o artigo Primeiro dessa Convenção, a paisagem cultural é uma obra conjugada do homem e da natureza. Pode ser um jardim, um vilarejo, uma paisagem relíquia, qualquer uma dessas paisagens é marcada pela sua história. Enfim, ela é uma "paisagem cultural associativa", ou seja, aquela na qual se associa o elemento natural a um fato religioso, artístico ou cultural.

Contudo, para conhecer as expressões impressas por uma cultura em suas paisagens e também compreendê-las, necessita-se de um conhecimento da "linguagem" empregada: os símbolos e seu significado nessa cultura. As igrejas, por exemplo, podem significar tanto o marco da presença da religião católica no local quanto a existência da casa de Deus para reunir os devotos; as cruzes são um símbolo do cristianismo e a presença delas ao longo das estradas assinala as mortes ocorridas por acidentes; velas, flores e comida em uma praia para os iniciados em candomblé significam oferendas para Iemanjá e, também, uma forma de pedir a ela o atendimento de um desejo; as mesquitas têm minaretes para que elas estejam visíveis e para que o muezzin possa chamar os fiéis para a prece.

Para ilustrar como a paisagem pode se constituir em objeto de estudo geográfico fascinante, foram escolhidos exemplos que manifestam o simbólico e a historicidade, a ressignificação na imaterialidade e o mito.

“Toda paisagem é simbólica", afirma Cosgrove (1998, p.106). De fato, se observados alguns exemplos, chegaremos a esta constatação: Brasília, para ilustrar, pode ser uma cidade como as demais, entretanto, é um símbolo poderoso do poder presidencial, de sede dos três poderes, unívoco. O lugar onde viveu uma figura nacional pode ser uma casa comum, porém, tem um significado simbólico enorme para os iniciados. É o caso da Casa Velha da Ponte, assim conhecida a casa em que viveu Cora Coralina, poetisa goiana, na cidade de Goiás. Uma cidade como Ouro Preto, tombada como patrimônio da humanidade, tem um significado simbólico intenso de um período da mineração do ouro, cujas marcas estão na imponência das igrejas e na arquitetura majestosa dos casarios. Brasília, Casa de Cora Coralina e Ouro Preto, embora paisagens distintas, são idênticas porque revelam a historicidade das relações entre a sociedade e a natureza e a concepção de mundo dos homens que as modelaram. No dizer de Santos (1997, p.83), a paisagem é “"[...] transtemporal, juntando objetos presentes e passados. É uma construção transversal."

Considerando outras paisagens, como as festivas, é evidente que a festa cívica participa plenamente do processo de construção simbólica das paisagens e dos territórios da localidade. A territorialização da festa rural, por exemplo, das folias, está delimitada pelo espaço da ornamentação de bandeirolas e de palmas ao longo dos caminhos; pelos arcos na entrada das casas e das fazendas; pelos ranchos de palha construídos para as prendas, para os leilões e para a venda de comida; pelos ranchos da festa e o trajeto da procissão; pelos pousos no percurso das folias ao fazer seus "giros"; pela presença da fogueira e pelo local definido para as danças da quadrilha e do forró. Esses elementos são testemunhos de que, na festa, notadamente nos desfiles e cavalgadas com seus pousos, 
itinerários mais ou menos fixos, há uma apropriação simbólica do espaço por uma coletividade. Essa apropriação produz o território e a identidade, conforme já foi dito. Diante de uma paisagem festiva, o olhar investe de toda a carga de experiências de uma vida e da existência humana, pois a paisagem, como afirma Schama (1996, p.23), reafirmando a historicidade apontada por Santos anteriormente, "[...] é um texto em que todas as gerações escrevem suas obsessões recorrentes".

Para Di Méo (2001), esse simbolismo festivo identifica e qualifica os lugares, os sítios, os monumentos, as paisagens e os lugares ordinários. Ritos e cerimônias destacam as ações dos grupos locais sobre o espaço da festa.

Mais que uma geografia concreta, porém, a festa engendra e constitui uma geografia simbólica e o espaço é revestido de uma dimensão mítica. Nos espaços rurais, conforme foi ilustrado, a festa contribui para forjar os territórios da localidade. Ela os constrói em torno dos universos políticos e ideológicos, tais como a cidade, o bairro, o povoado, a fazenda. Nessas configurações, a lógica econômica participa, mas a história e a memória contam com todo o seu peso. As paisagens emergem segundo as experiências e as percepções de cada indivíduo.

Há casos de paisagem, porém, em que o simbolismo não é tão evidente. No Equador, a capital Quito encontra-se no sopé do vulcão Pichincha. Além dele, na mesma Cordilheira Ocidental, encontra-se o pico mais alto do país, o vulcão Chimborazo (6.268 metros, apelidado de Taita Chimborazo, ou seja, papai Chimborazo). A cadeia montanhosa oriental é formada pela majestosa Cordilheira Real cheia de altas montanhas e alguns vulcões ainda ativos entre os quais o Tungurahua (5.023 metros) conhecido como mama Tungurahua, cuja última atividade ocorreu em 2008.

Entremeadas por um longo vale e margeada por pequenos vilarejos indígenas, a região foi batizada por Alexander Von Humboldt, no século XIX, de "Avenida dos Vulcões" (2001). Esse lugar tornou-se, na atualidade, um roteiro turístico de larga demanda pelos ansiosos viajantes por se defrontarem com um vulcão expulsando material incandescente, lavas piroclásticas e gases. Avenida é uma expressão que define bem esse território salpicado de "gigantes" que se expõem soberanos e determinam a paisagem. Nesse território, existe cerca de 30 montanhas de origem vulcânica. Muitos desses vulcões ainda permanecem ativos e a cidade de Latacunga já foi devastada duas vezes pela erupção do Cotopaxi. A palavra Cotopaxi, herdada do antigo dialeto Inca, vem da composição de duas palavras: "Coello de la Luna", ou "Garganta da lua". Em uma época do ano, a lua cheia nasce, vista de Quito, exatamente em cima do vulcão, o que justifica considerá-lo como uma garganta daquele astro. Os mitos ajudam a estabelecer um padrão de convivência com os imponentes, temidos e belos vulcões. Para Schama (1996), quando uma determinada ideia de um mito ou de uma visão se forma em um lugar concreto, ela torna as metáforas mais reais que seus referentes, tornando-se de fato parte da paisagem.

Essas são algumas paisagens simbólicas do Equador. O geógrafo atual não estuda mais apenas a paisagem como realidade objetiva como Humboldt o fez no século XIX. O seu olhar dirige-se para perceber a paisagem carregada de sentido, investida de significados por aqueles que vivem nela ou que a descobrem. Neste processo, Duncan também opina, dizendo que "[...] a paisagem é lida como um texto, e então atua como um elemento de transmissão, reproduzindo a ordem social" (DUNCAN, 2004, p.111). O que impulsiona as pessoas a permanecerem nos lugares próximos aos vulcões? O que fazem as pessoas sonharem com a avenida dos vulcões? Por que as pessoas consideram alguns acidentes da topografia, certas construções como especiais, como elementos de um patrimônio, sacralizando esses territórios? Essas questões dizem respeito a como os homens apropriam-se do meio ambiente e o transformam, produzindo as paisagens.

Breve, a paisagem testemunha a aventura do homem na superfície da terra e qualquer marca por ele introduzida significa um diferente valor cultural. Técnicas, crenças religiosas e ideológicas perpassam cada paisagem, por isso, as paisagens possuem significados simbólicos e estão, também, carregadas de ideologias. São reconhecidas como testemunhas da criatividade, da diversidade cultural, dos cenários de vida e tornam-se objetos de interesse de políticas nacionais e internacionais. 
No caso de paisagens culturais, o Brasil ainda carece de uma legislação específica que atenda às recomendações da UNESCO a despeito de ser signatário da Convenção Relativa à Proteção do Patrimônio Mundial Cultural e Natural de 1972. O Brasil assumiu o compromisso ético de proteger os bens inscritos na lista do Patrimônio Mundial. O desamparo não é completo porque na Constituição Brasileira de 1988, no seu artigo 216, define-se o patrimônio cultural brasileiro e, no inciso V, são definidos “os conjuntos urbanos e sítios de valor histórico, paisagístico (grifo nosso), artístico, arqueológico....". Isso revela que a paisagem é percebida como um dos elementos centrais na cultura; um conjunto ordenado de objetos passível de ser interpretado, repetimos, como um texto e que atua como uma criadora de signos pelos quais um sistema social é transmitido, reproduzido, vivenciado e explorado.

Sem entrar no mérito da intencionalidade desse fato, desde então, atores diversos têm se apropriado do termo: organismos não governamentais, terceiro setor, técnicos governamentais, pesquisadores e a sociedade civil. As paisagens culturais transformam-se em objetos de políticas valorativas, preservacionistas e, também, de atrações turísticas. Para ilustrar, no ano de 2008, houve uma iniciativa do Instituto de Patrimônio Histórico e Artístico Nacional - IPHAN - em inaugurar o conceito de paisagem cultural na criação dos Roteiros Nacionais de Imigração. Isso ocorreu no dia 27 de agosto, em Pomerode, Santa Catarina. Conforme Barreto (2010), “os Roteiros Nacionais de Imigração" ressaltam os elementos paisagísticos das estradas rurais de Santa Catarina e os costumes e tradições seculares trazidos pelos imigrantes: a culinária, a música, os dialetos, a arquitetura, as festividades. Paisagens culturais passam a ser reconhecidas como representativas de uma história nacional e como valorizadoras da presença do imigrante naquele estado brasileiro.

Ainda é o IPHAN que mais recentemente tomou a iniciativa de estabelecer a chancela da Paisagem Cultural Brasileira, publicando no Diário Oficial da União de 05 de maio de 2009, a Portaria 127 , de 30 de abril de 2009. Por ela, considera-se a paisagem cultural "como uma porção peculiar do território nacional, representativa do processo de interação do homem com o meio natural, à qual a vida e a ciência humana imprimiram marcas ou atribuíram valores"(apud WEISSHEIMER, 2010). A chancela tem por finalidade atender o interesse público e contribuir para a preservação do patrimônio cultural, complementando os instrumentos de promoção e proteção já existentes e integrando-os.

Para finalizar, Andreotti (2008) afirma que, na paisagem, refletem-se a filosofia, a religião, a ciência. Nesse sentido, a paisagem cultural é testemunha de cultura, de história, de religião, de ideologias e de arte. Simultaneamente, ela é a inspiração e a inspiradora e, quando estamos diante de uma paisagem cultural, percebemos imediatamente a íntima conexão entre as várias formas de vida espiritual que a gerou. Nisto ela se distingue da paisagem geográfica, pois é dotada de anima, de algo profundo e interior, a alma. Os múltiplos significados das paisagens simbólicas falam, pois, muito dos homens que as criaram. Elas explicam a diversidade cultural do mundo em que vivemos.

\section{DELINEANDO UMA CARTOGRAFIA CULTURAL}

Sem a pretensão de delinear uma "cartografia cultural”, mas ao contrário, entendendo-a como uma construção social (MARTINELLI, 1991), como modo de representar, comunicar e espacializar conteúdos tratados por estudiosos da geografia cultural, o desfecho deste artigo apresenta alguns aspectos merecedores de reflexão. Sem dúvidas, a cartografia é mais entendida pelo balizamento matemático de posição, situação, localização do que pela representação de imagens, percepções, vivências das representações e práticas culturais parte das quais trataremos a seguir.

A pluralidade de abordagens e de possibilidades aqui apresentadas remete-nos à fonte inspiradora dessas reflexões sobre os procedimentos de uma cartografia cultural, traçados por Claval (2008), ao analisar as "famílias" da abordagem cultural, quais sejam o estudo das representações, a análise da experiência vivida e a descrição dos processos culturais e socioculturais. Claval (2008, p. 28-29) assinala que "[...] o tempo das discussões sobre a utilidade da abordagem cultural já está 
ultrapassado [...], a coexistência de três famílias de abordagem cultural não é incômoda. Ela permite aos geógrafos de sensibilidade diversas formas de expressão".

Poder-se-ia, então, afirmar para o processo construtivo de uma a cartografia cultural o que Claval assinala para a abordagem cultural? A parca produção cartográfica de estudos culturais traduz uma desvalorização ou uma dificuldade na representação das realidades/abordagens culturais? Quando feita, estamos representando cartograficamente com sensibilidade?

Não há respostas prontas e definitivas para essas indagações, mas talvez, pistas indicativas de que muito estamos deixando de produzir, ou melhor, de mais facilmente comunicar, mostrar, demonstrar e explicitar a representação simbólica que mapas e cartogramas oferecem. É nesse sentido que Seemann (2003, p. 278) entende a apresentação dessas "cartografias culturais", ainda pouco definidas, mas que, mesmo assim, "[...] pode abrir caminhos, não apenas para revelar a imensa variedade cultural no Brasil, mas também "escavar" as inúmeras maneiras de pensar e representar o espaço".

Para ilustrar os esforços que vêm sendo feitos, apresentamos o processo de definição da cartografia para um inventário cultural. Tal como no Estado da Bahia, a Secretaria de Planejamento de Sergipe definiu seus Territórios de Identidade e solicitou-nos um inventário cultural com vistas à elaboração de um atlas cultural, base para a montagem de ações voltadas para a identidade, a cultura e o desenvolvimento. Ora, como inventariar sem a precedência de um debate sobre as expressões culturais e as identidades? Seriam os Territórios de Identidade palco da materialização das expressões culturais e estas conformadoras dos territórios? Dito em outras palavras, os Territórios de Identidade do planejamento permitem aproximações com os aspectos culturais identitários?

Tais questionamentos foram expostos de forma a ressaltar um aspecto importante na construção da cartografia de manifestações culturais: o momento de definição do estudo e a consideração dos conceitos trabalhados como definidores do processo do mapeamento. Isso implica a construção conjunta do balizamento teórico e metodológico da pesquisa com a cartografia, da observação do geógrafo com a cartografia, ou seja, esta não decorre do produto da pesquisa ou do texto, é parte integrante do processo de construção. Se a produção cultural é formadora do espaço, seu mapeamento é, já o dissemos, também, uma construção social, como afirma Martinelli (1991), que articula a construção material e a construção simbólica do espaço (MORAES, 2005).

Como assinalado por Claval (2008), as abordagens e expressões são diversas e, nesse sentido, há também que se considerar que um estudo, mesmo no âmbito de um inventário, não expressa um todo coerente e estruturado que possa ser nomeado como síntese da cultura, seja sergipana, baiana ou peruana, formato e retrato de suas identidades. Integrantes do universo simbólico, cultura e identidade são múltiplas. Além disso, existem diferentes formas de interpretação e apropriação e, por conseguinte, de expressão cartográfica.

O delineamento da cartografia das manifestações culturais elaborada no estudo sergipano (VARGAS; NEVES, 2009) partiu, em primeiro lugar, do entendimento de que a listagem das práticas culturais não nos permitiria automaticamente acessar a identidade de um grupo ou de um Território de Identidade, pois as práticas e manifestações culturais podem ou não ser produzidas em torno de identidades, embora marquem as experiências e, em geral, participem do processo de percepção do mundo pelos sujeitos. Dessa maneira, vislumbrou-se um levantamento pensado e executado de forma aberta e flexível, sem pretensão de expor a base da cultura sergipana, mas com o foco na expressão de como a cultura é praticada pela população, que produz culturas (GEERTZ, 1989); que produz práticas culturais, às vezes, tradicionais, às vezes, de forma ressignificada, seja das práticas tradicionais seja das práticas contemporâneas e/ou globalizadas.

Em segundo lugar, considerou-se que as práticas e expressões culturais marcam as experiências dos sujeitos, ao mesmo tempo em que são resultados de ações e também meio para os sujeitos repensarem suas ações. Assim, práticas culturais marcam de forma profunda os sujeitos atores, embora nem sempre visíveis ao primeiro olhar. 
Dessa forma, optou-se pelo mapeamento das expressões da cultura imaterial, considerando: i) as manifestações tradicionais enraizadas como aquelas que traduzem a herança e a manutenção das práticas tal como apropriadas no passado; ii) as manifestações ressignificadas/contemporâneas como aquelas cuja evolução apresentou variações na composição e na estrutura, ou ainda, aquelas inovadoras, recentes e decorrentes de externalidades múltiplas.

Com esse arcabouço, delineou-se uma interpretação e uma expressão semiótica com implantação cartográfica dos tipos de manifestações acima descritos de acordo com suas representações para o lugar, ou seja, foram definidas as categorias de representação que possibilitaram a construção da seguinte legenda: a) aquelas que mobilizam a comunidade e/ou expressam o lugar, mapeados com a cor vermelha; b) aquelas que são importantes, sobretudo, para os grupos que as produzem, mapeados com a cor laranja e, c) aquelas que são do passado, não existem mais, mapeados com a cor azul. A decisão de mapear as manifestações do passado decorreu dos objetivos do estudo em abordar transversalmente, identidade e cultura e, nesse sentido, a espacialização do "avesso do presente" foi posta para a compreensão ressignificada do que se produz e, contemporaneamente, como recurso valioso da interpretação do que se constrói e se produz no presente.

A "passagem" das categorias de representação para o mapa é ilustrada na Figura 1 que mostra um extrato da matriz semiótica e o mapa com a espacialização da manifestação "dança de roda".

\begin{tabular}{|l|l|l|l|l|l|}
\hline $\begin{array}{l}\text { Municipios/ } \\
\text { Manifestações } \\
\text { tradicionais }\end{array}$ & A & B & C & D & E \\
\hline Quadrilha & & & & & \\
\hline Reisado & & & & & \\
\hline Cavalhada & & & & & - \\
\hline $\begin{array}{l}\text { Samba de } \\
\text { coco }\end{array}$ & & & & - & - \\
\hline
\end{tabular}

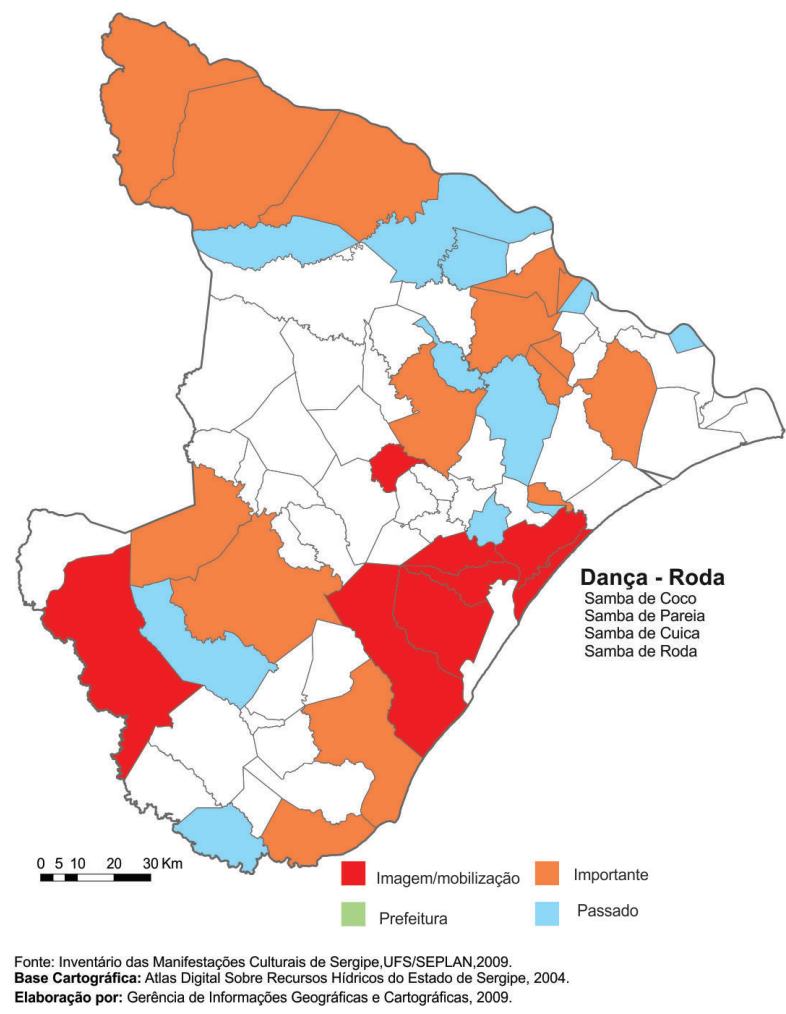

Figura 1 - Sergipe, Manifestações Culturais Tradicionais Enraizadas - 2009

Optou-se por tal implantação de forma a facilitar a visualização do conjunto de manifestações levantadas, mas também, agrupamentos e especificidades. As intensidades de cores propostas, vermelha/laranja, e distinção da cor azul constituíram neste mapeamento um sistema de signos que proporcionou a apreensão de relações de semelhança, de ordem e de quantidade das manifestações culturais. 
Embora os resultados desse estudo não estejam na delimitação desse artigo, vale afirmar nosso entendimento de que a distinção entre identidade cultural e identidade territorial (dos Territórios de Identidade) pode ser de grande valia para a compreensão da dinâmica do processo de construção de identidades locais e dos Territórios de planejamento nos estados em que foram instituídos. Entendemos que, nesse sentido, o território tanto é habitado por culturas como também por "olhares forjados cultural e politicamente", práticas e ações que delimitam e dão vida aos territórios. Mas essas "questões" podem vir a ser objeto de outras discussões.

Chamamos a atenção para a estreita relação entre a definição dessas cores e a intensidade de cores com a metodologia do estudo e assinalamos a importância dada ao processo de mapeamento e não propriamente ao produto final, as matrizes e os mapas. Interessou mais traçar e representar os conceitos de expressões e manifestações tradicionais enraizadas e ressignificadas, assim como as conexões no tempo (do presente e do passado), e no espaço. Ou seja, o processo cartográfico foi conduzido pela perspectiva do inventário proposto para o mapeamento das manifestações culturais tradicionais e ressignificadas, expressas pelos sujeitos pesquisados que evidenciam aquelas importantes para os grupos que as produzem, ou então, as do passado que ainda permanecem em suas memórias.

\section{CONSIDERAÇÕES FINAIS}

Depreende-se pelo que foi exposto que tanto a paisagem quanto o território são dimensões marcadas por elementos patrimoniais, signos da trajetória da sociedade que ativam a memória e situam os grupos definindo suas identidades.

Tais dimensões são produtos e, ao mesmo tempo, produtoras da natureza social e cultural das sociedades. Com isso, não se afirma que as ações dos homens sejam determinadas pela moldura material do meio ambiente, mas ressaltam-se as imbricações que existem e permeiam as paisagens culturais. Elas refletem a superposição de poderes e de símbolos dos homens (GANDY, 2004). Elas são, pois, poderosos elementos constitutivos das visões de mundo e de nós mesmos.

Considerando-se que o mapa é uma representação da realidade, uma expressão simbólica do mundo sociofísico, procuramos, com as tipologias engendradas, trazer um sistema simples de codificação, de forma a possibilitar leitura fácil e acessibilidade de significados. A cartografia produzida constituiu, em última instância, um produto circunscrito a uma linguagem. Ele está aberto para estudos e aprofundamentos sobre o significado e as representações da cultura, no caso, a cultura sergipana, mas que se mostra passível de aplicação a outros estudos.

Ainda distantes de uma produção cartográfica atada à densidade da produção da geografia cultural, reafirmamos a importância de sua construção consonante aos conceitos e abordagem do estudo proposto: que a paisagem expresse não apenas elementos patrimoniais, mas também signos da trajetória da sociedade; que sua cartografia não expresse apenas a unicidade, mas, sobretudo, a multiplicidade de sentidos.

Assim, a perspectiva de análise aqui empreendida reafirma a importância de se considerar nas "leituras geográficas", além das dimensões mais objetivas, os aspectos voltados para a subjetividade e para a simbologia dos territórios e paisagens. Espera-se que tal caminho possa continuar suscitando debates e despertando novas possibilidades de percursos.

\section{REFERÊNCIA BIBLIOGRÁFICA}

ALMEIDA, M. G. de; VARGAS, M. A. M. A dimensão cultural do sertão sergipano. In: DINIZ, J. A. F.; FRANÇA, V. L. A. (Org.). Capítulos de geografia nordestina. Aracaju: NPGEO/UFS, 1998. p. 469-485.

ALMEIDA, M. G. de. Em busca do poético do sertão: um estudo de representações. In: ALMEIDA, M. G. de; RATTS, A. J. P. (Org.). Geografia: leituras culturais. Goiânia: Alternativa, 2003. p. 71-88. 
ALMEIDA, M. G. de. Fronteiras, territórios e territorialidades. Revista da ANPEGE. Fortaleza, ano 2, n. 2, 2005, p. 103-114.

ALMEIDA, M. G. de. Diversidade paisagística e identidades territoriais e culturais: Brasil sertanejo. In: ALMEIDA, M. G. de; CHAVEIRO, E. F.; BRAGA, H. C. (Org.). Geografia e cultura: a vida dos lugares e os lugares da vida. Goiânia: Editora Vieira, 2008. p. 47-74.

ANDREOTTI, G. Per una architettura del paesaggio. Trento: Valentina Trentini Editore, 2008.

BAHIA. Governador (2007: Jaques Wagner). Secretaria do Planejamento (SEPLAN) e Superintendência de Estudos Econômicos e Sociais da Bahia (SEI). Territórios de Identidade. Salvador, 2008.

BHABHA. H. K. O local da cultura. Belo Horizonte: Ed. UFMG, 1998.

BARRETO, P.H. Uma herança a ser preservada. Desafios do desenvolvimento. Edição especial. IPEA. Junho/Julho 2010, ano7, n. 62, p.22-24.

CLAVAL, P. A Paisagem dos Geógrafos. In: CORREA, R.L. ROSENDAHL, Z. (Org.). Paisagens, textos e identidade. Rio de Janeiro: Editora da UERJ, 2004, p.13-74.

CLAVAL, P. A Geografia Cultural. Florianópolis: Editora da UFSC, 2001.

CLAVAL, P. Uma, ou Algumas, Abordagem(ns) Cultura (is) na Geografia Humana? In: SERPA, A. (Org.) Espaços culturais: vivências, imaginações e representações. Salvador: EDUFBA, 2008.

CLIFFORD, J. Dilemas de la cultura. Barcelona: Gedisa, 1995.

COSGROVE, D. A geografia está em toda parte: cultura e simbolismo nas paisagens humanas. In: CORREA, R. L, ROSENDAHL, Z. (Org.) Paisagem, Tempo e Cultura. Rio de Janeiro: EdUERJ, 1998. p.84-122.

DEL RÍO, J. M. V. Fronteras, territorios e identificaciones colectivas. Sevilla: Fundación Blasifante, 1998.

DI MÉO, G. La géographie en fêtes. GAP: Ophrys, 2001

DUNCAN, James. A paisagem como sistema de criaçao de signos. In: CORREA, R. L. ROSENDAHL, Z. (Org.). Paisagens, textos e identidade. Rio de Janeiro: EdUERJ, 2004, p. 91-132.

GANDY, M. Paisagem, estéticas e ideologia. CORREA, R. L. ROSENDAHL, Z. (Org.). Paisagens, textos e identidade. Rio de Janeiro: EdUERJ, 2004, p.75-90.

GARCÍA CANCLINI, N. Consumidores e cidadãos: conflitos multiculturais da globalização. 6 ed. Rio de Janeiro: Editora UFRJ, 2006.

GEERTZ, C. A interpretação das culturas. Rio de Janeiro: LTC, 1989.

HALL, S. A identidade cultural na pós-modernidade. 3 ed. Rio de Janeiro: DP\&A, 1999.

HAESBAERT. R. Identidades Territoriais. In: CORREAA, R. L.; ROSENDAHL, Z. (Org.). Manifestações da cultura no espaço. Rio de Janeiro: EdUERJ, 1999. p. 169-190.

HAESBAERT. R. O mito da desterritorialização: do "fim dos territórios" à multiterritorialidade. Rio de Janeiro: Bertrand Brasil, 2004.

HUMBOLDT,Von A. Ensayo de una descripción física del mundo. Rio de Janeiro: Zahar Editora.Tomo II, 2001.

KEROUAC, J. On the road: pé na estrada. Porto Alegre. Coleção P\&M Pocket. 2006.

MASSEY, D. Pelo espaço: uma nova política da espacialidade. Rio de Janeiro: Bertrand Brasil, 2008.

MARTINELLI, M. Curso de cartografia temática. São Paulo: Contexto, 1991.

MELO, A. F. de. O Lugar-Sertão: grafias e rasuras. 2006. 131 f. Dissertação (Mestrado em Geografia) Instituto de Geociências, Universidade Federal de Minas Gerais. Belo Horizonte, 2006.

MENDES. G. F. Sertão se traz na alma? Território/lugar, memória e representações sociais. 2009. 250f. Tese (Doutorado em Geografia) - Núcleo de Pós-Graduação, Universidade Federal de Sergipe. São Cristóvão, 2009.

MORAES, A. C. R. de. Território e história no Brasil. São Paulo: Annablume, 2005.

PENNA, M. O que faz ser nordestino: identidades sociais, interesses e o "escândalo" Erundina. São Paulo: Cortez, 1992.

PESAVENTO. S. J. Muito além do espaço: por uma história cultural do urbano. Estudos Históricos. Rio de Janeiro, v. 8, n. 16, 1995, p. 279-290. 
SANTOS, M. A natureza do espaço: técnica e tempo-razão e emoção. 2 ed. São Paulo: Hucitec, 1997. SAQUET, M. A. Abordagens e concepções sobre territórios. São Paulo: Expressão Popular, 2007.

SCHAMA, S. Paisagem e Memória. São Paulo: Companhia das Letras, 1996.

SEEMANN, J. Mapeando culturas e espaços: uma revisão para a geografia cultural no Brasil. In: ALMEIDA, M. G. de; RATTS, A. J. P. (Org.). Geografia: leituras culturais. Goiânia: Alternativa, 2003. p. 261-284. SERPA, A. O trabalho de campo em geografia: uma abordagem teórico-metodológica. Boletim Paulista de Geografia. São Paulo, n. 84, p. 7-24. 2006.

TUAN, Y. Espaço e Lugar. São Paulo: Difel, 1983.

VARGAS, M. A. M.; NEVES, P. S. da C. Inventário de cada um dos oito territórios de Sergipe e elaboração de um Atlas da cultura sergipana. Relatório de Pesquisa. Aracaju: Seplan, 2009.

WEISSHEIMER, M.R. A chancela da Paisagem Cultural: uma estratégia para o futuro. Desafios do desenvolvimento. Edição especial. IPEA. Junho/Julho 2010, ano 7, n. 62, p. 25.

Trabalho enviado em maio de 2011 Trabalho aceito em agosto de 2011 